\title{
Organ Printing: a novel tissue engineering paradigm
}

Today:

The number of medical devices implanted in human bodies is surging. Nearly half a million coronary stents - metal gadgets to hold arteries open are installed in human chests each year in the United States. There are 325,000 knee replacements every year, 165,000 artificial hips, 177,000 cardiac pacemakers and 2.5 million eye lenses after cataract surgery. About 46,000 people a year get internal cardiac defibrillators to treat excessive heart rate. 


\title{
Today (in the USA alone):
}

Demand for replacement organs

\author{
78,000 kidney \\ 4,000 heart \\ 19,000 liver \\ 450,000 cardiac bypass surgery (arteries) \\ 100,000 leg arteries bypass \\ 350,000 dialysis access
}

A number of those on the waiting list die before a solution can be found. If no remedy to these problems is soon found, the situation will become critical in the not so distant future (in your lifetime). 


\section{Today:}

Source for replacement organs

Matching donors

Cadavers

Xenotransplantation

Artificial organs

Tissue engineering-

Regenerative medicine
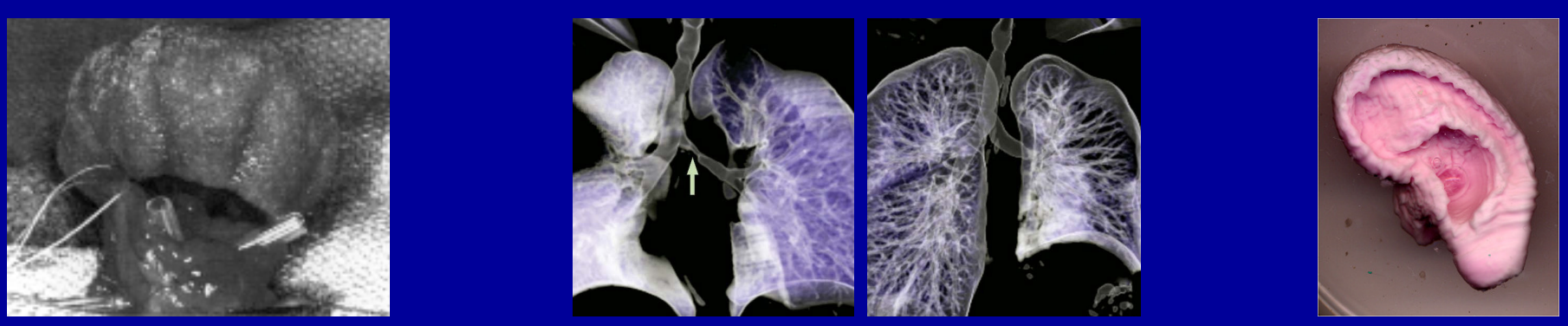
Glimpse into what is coming

The Tomorrow: building organs by printing

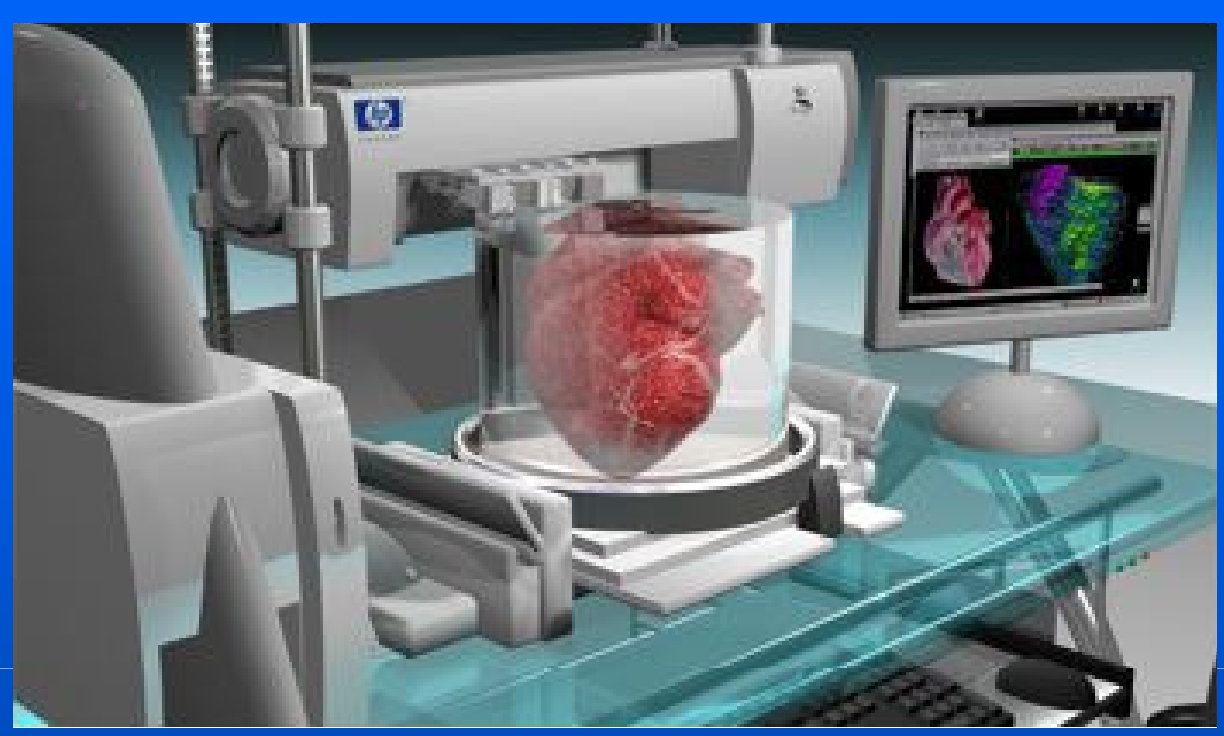

Rapid prototyping biofabrication methods Bioprinting

The bioink

The biopaper

The bioprinter

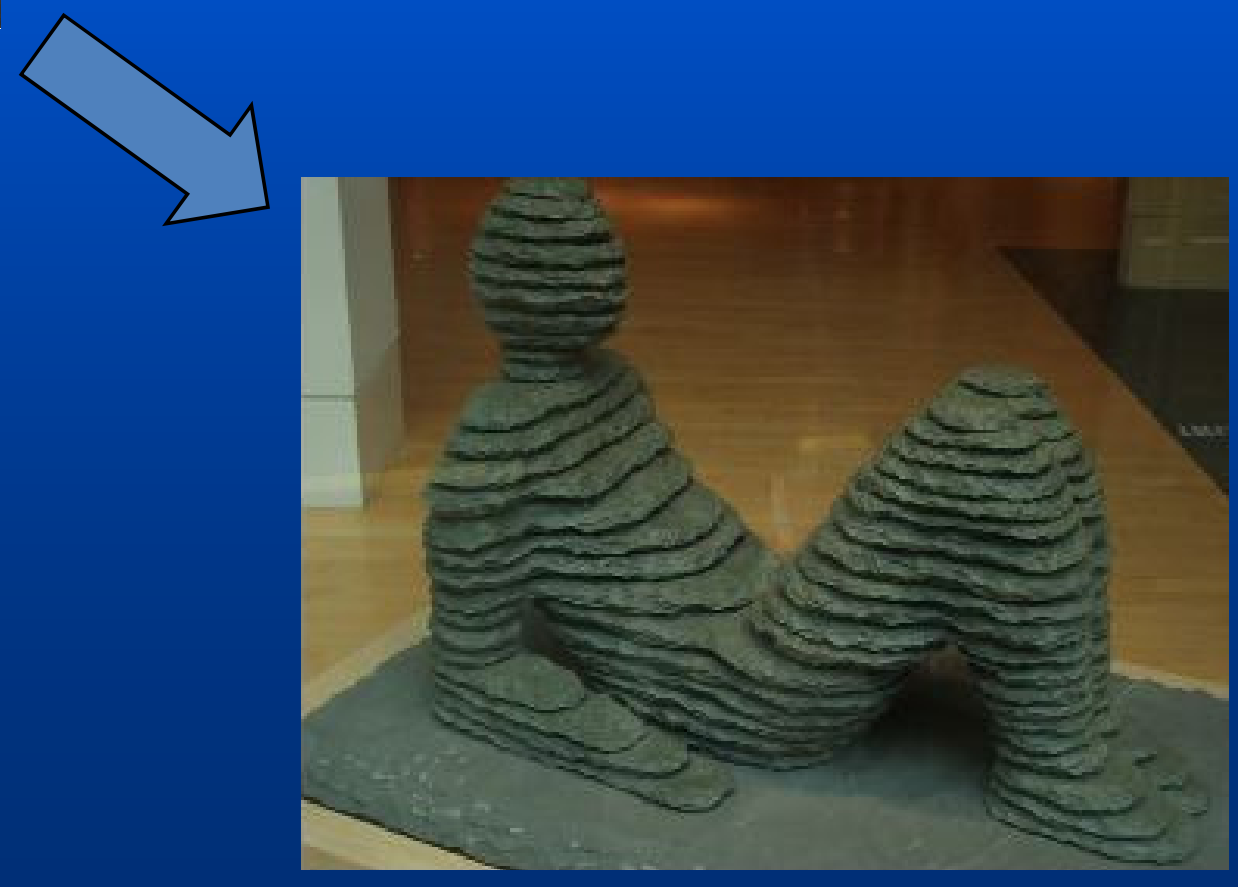


Organ Printing Technology Developed at MU, licenced to Organovo, Inc.
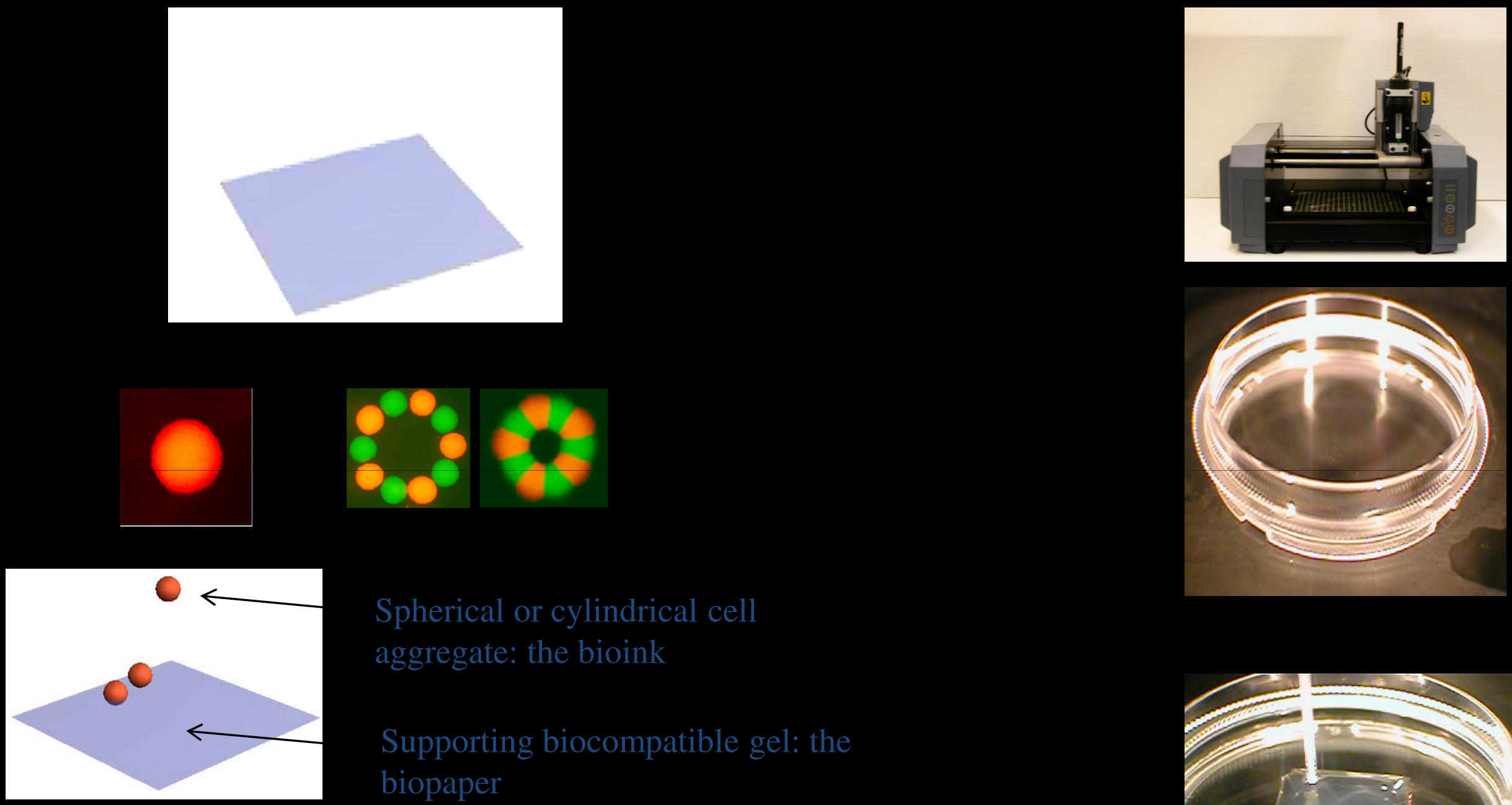

Spherical or cylindrical cell aggregate: the bioink

Supporting biocompatible gel: the biopaper

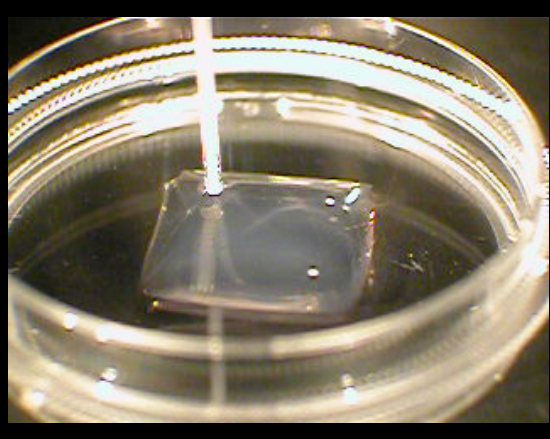


Organ Printing Technology Developed at MU, licenced to Organovo, Inc. (Scaffoldless technology, based on developmental principles; fusion, cell sorting)
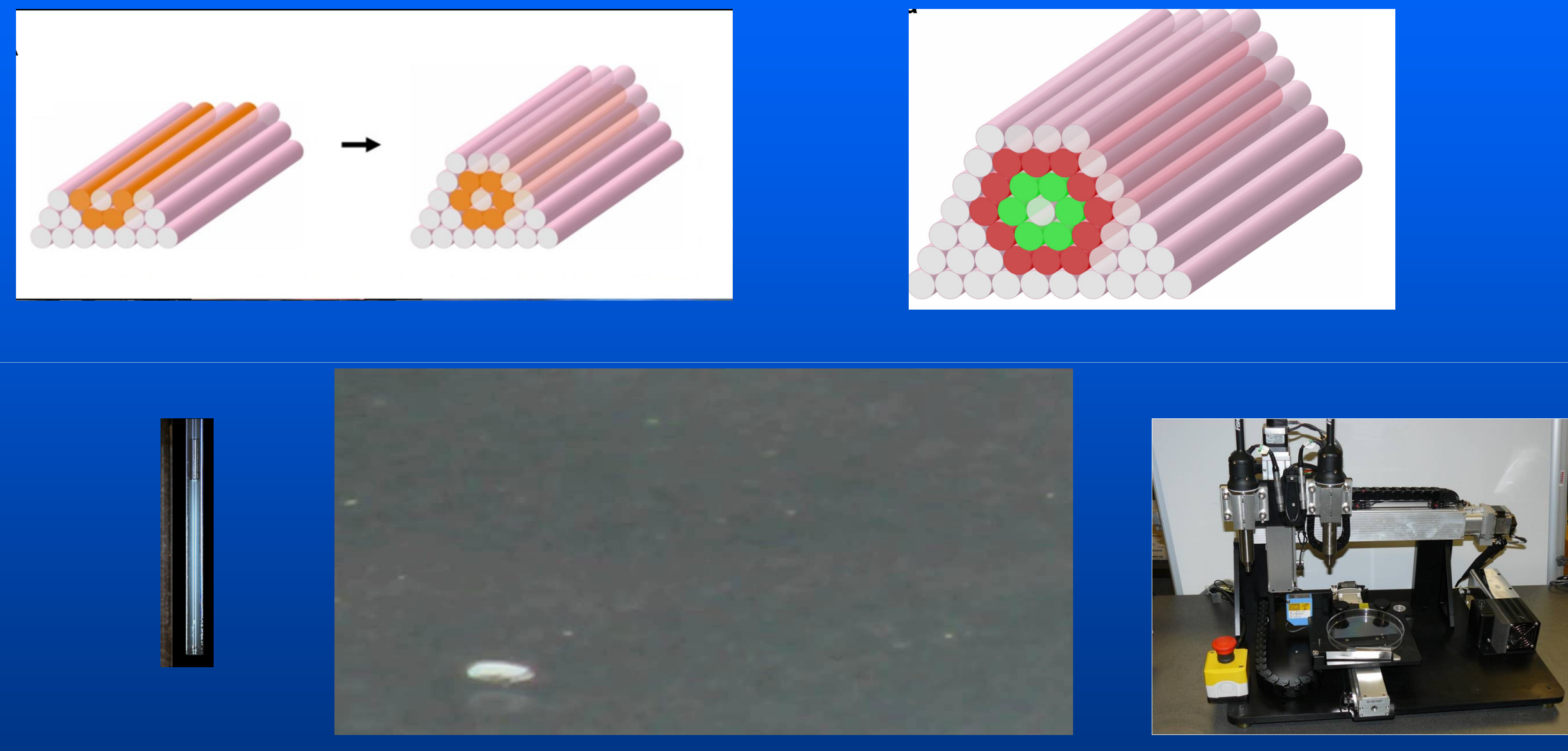

Novogen Printer 
After Printing, Blood Vessels Are Matured in Bioreactors
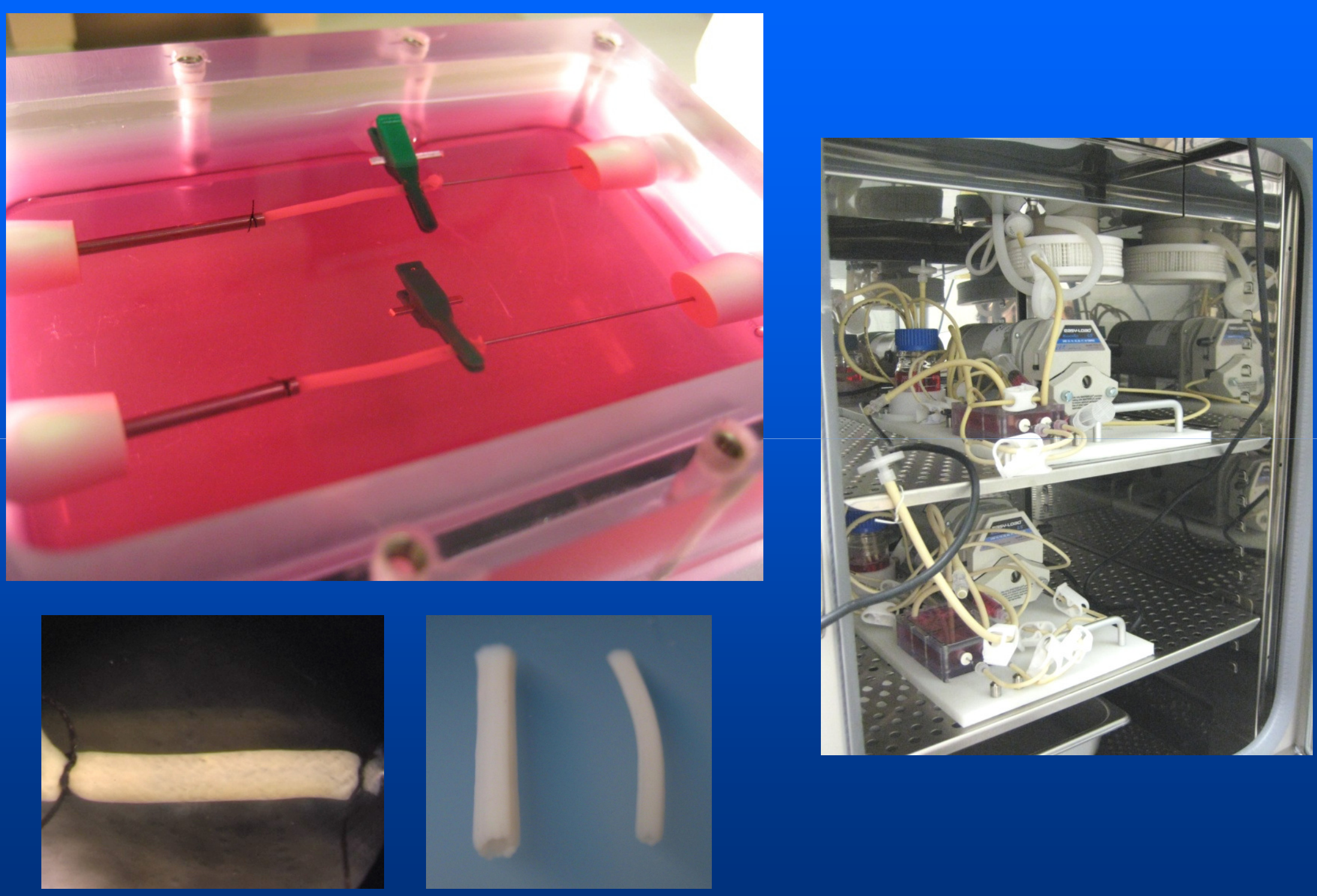


\section{Other graft products}

Branching tubes

Nerve grafts
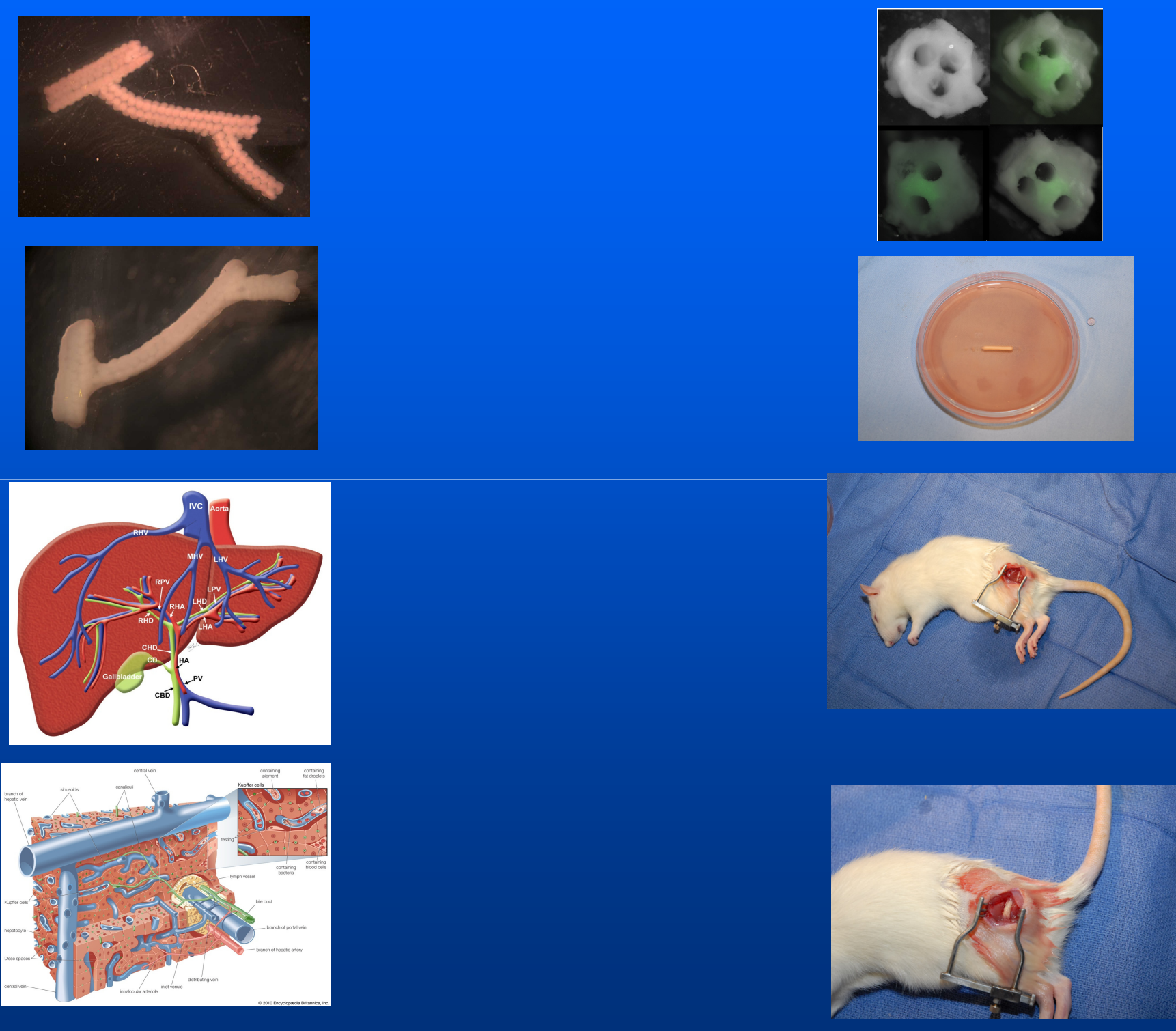
Functional Myocardial Graft
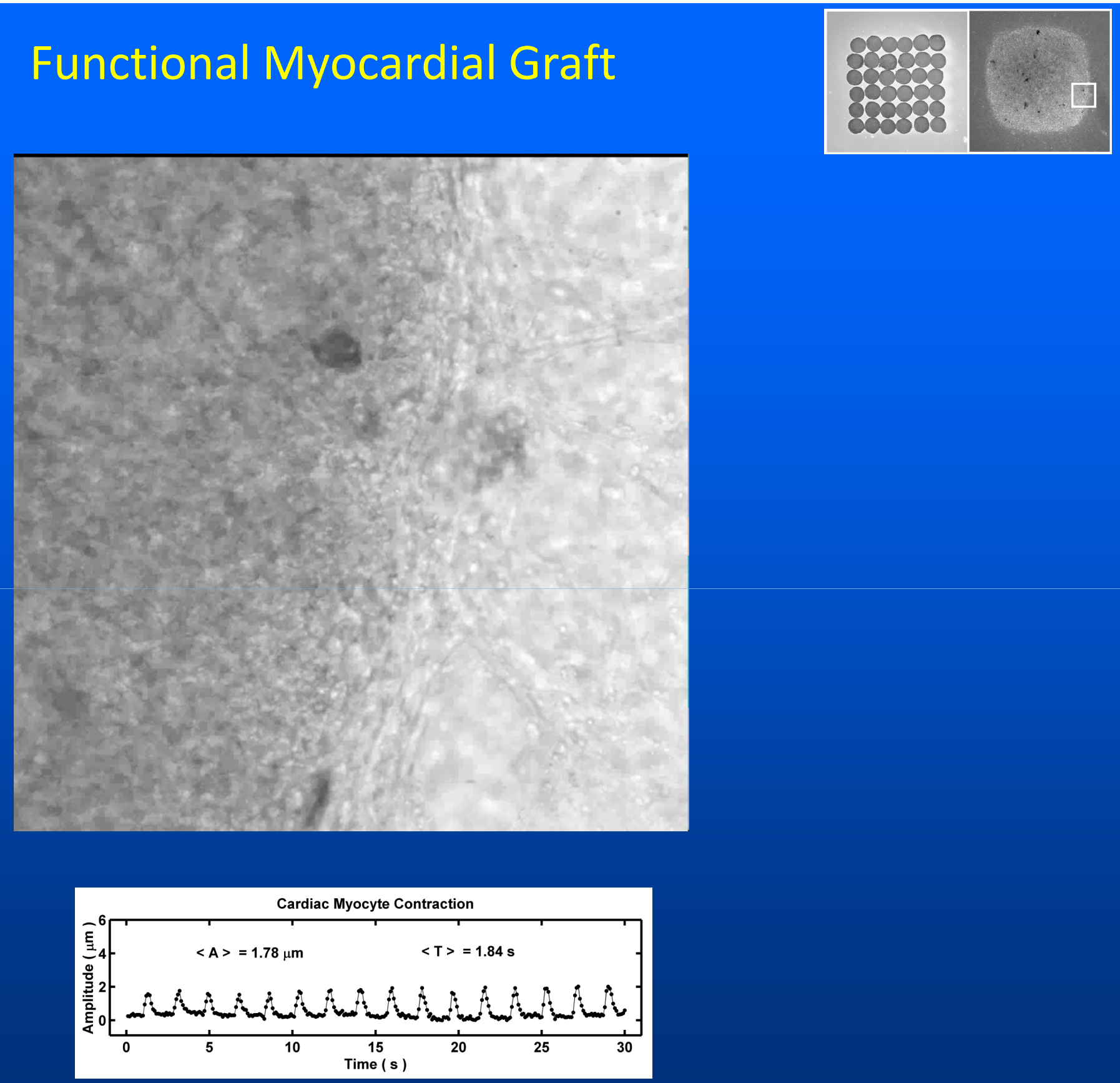


\section{Vascular Health Presents Several Sets Of Large And Growing Opportunities For Medical Innovation}

\section{First Markets}

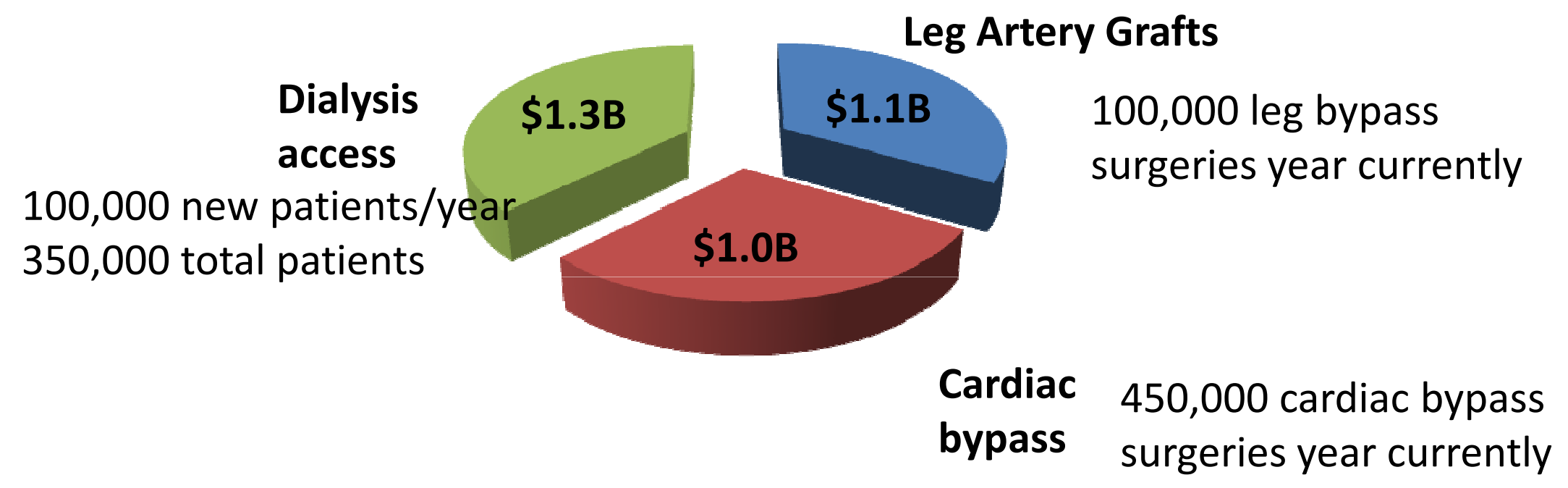

>\$3B Global Opportunity 
Organovo's Bioprinter Technology Now Ready for Wide Use

\section{Invetech}

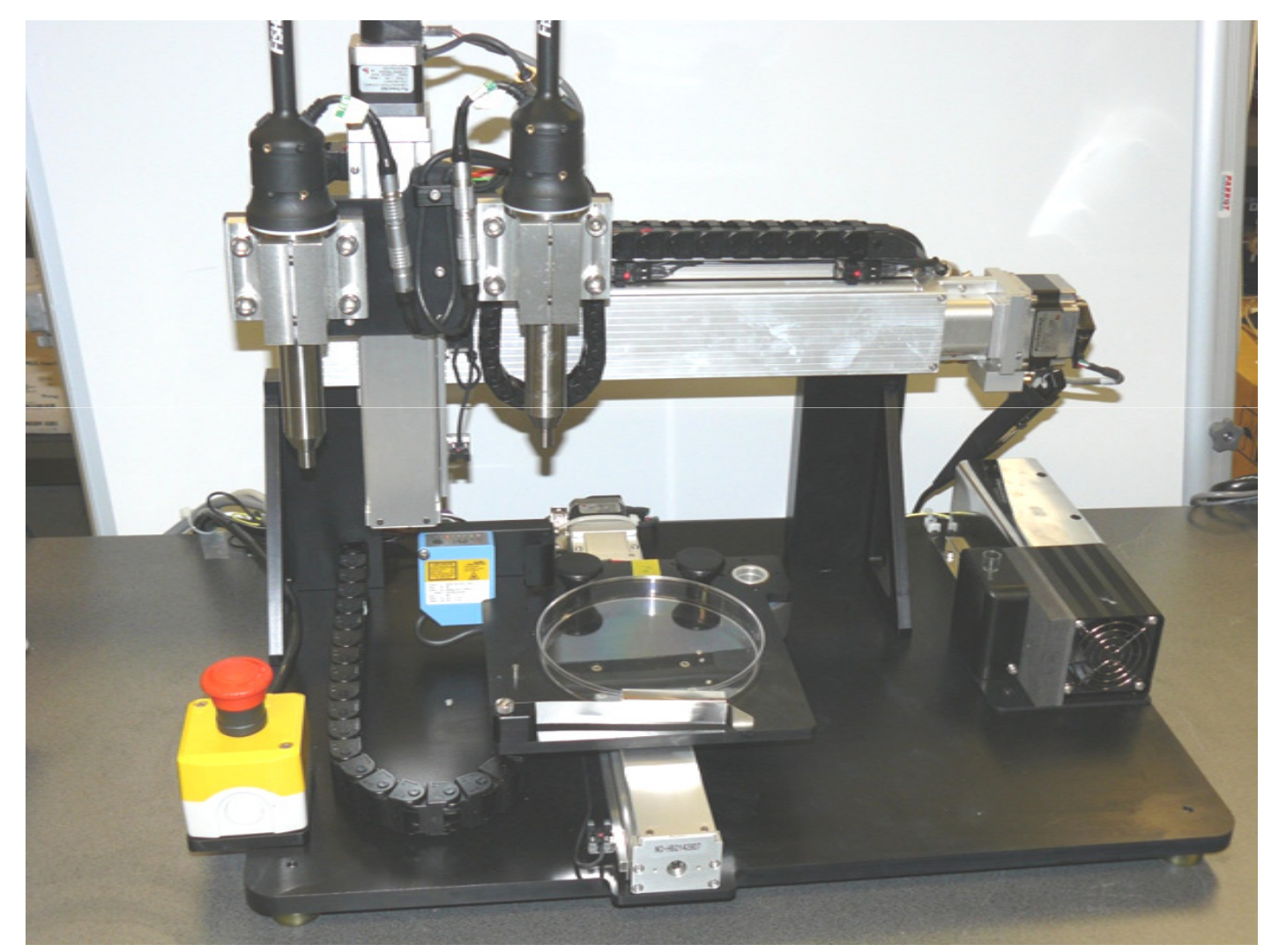


Organovo Bioprinter Sales Can Be Driven by Key Opinion Leader Sites
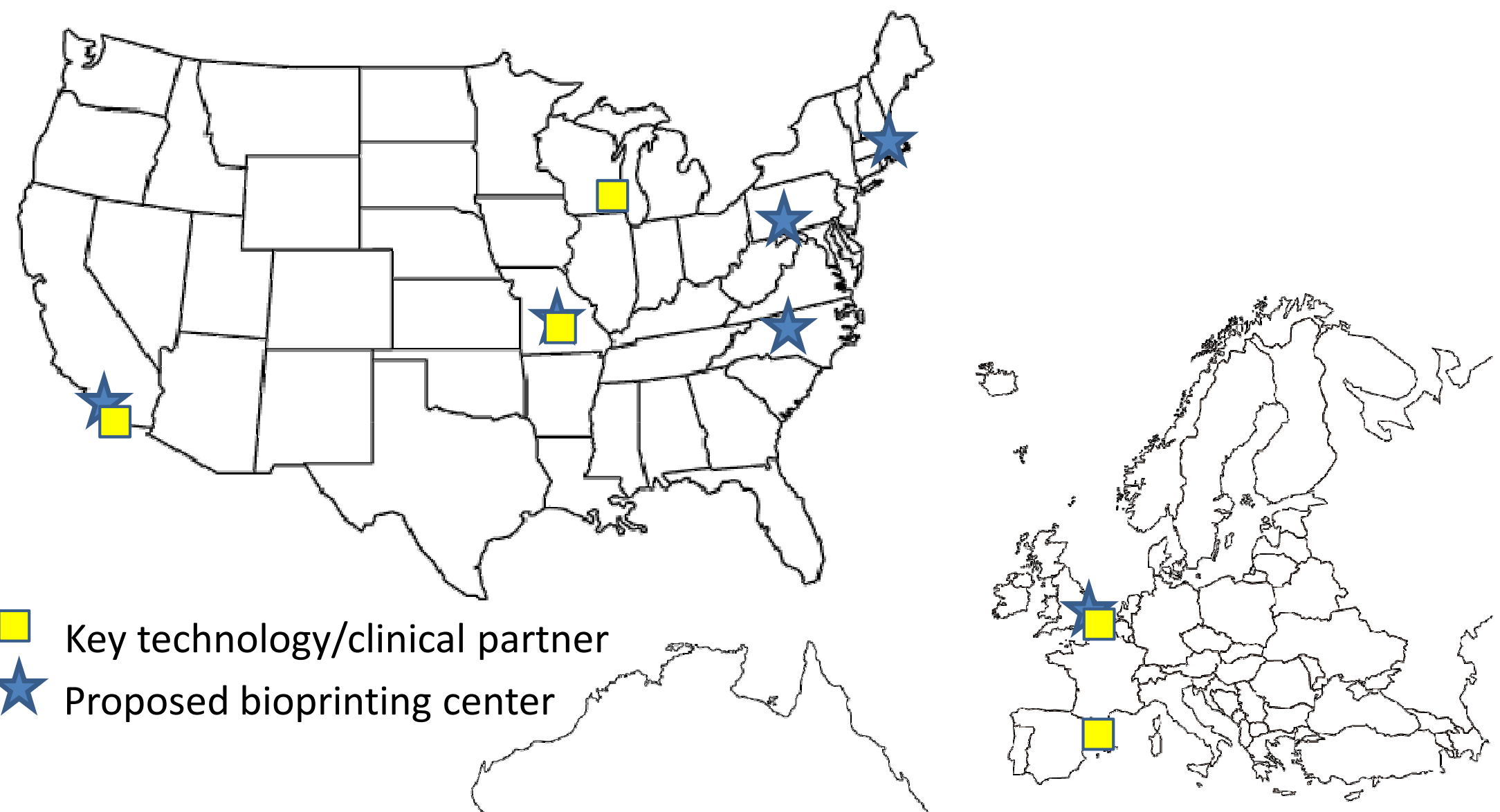

$\square$ Key technology/clinical partner

th Proposed bioprinting center

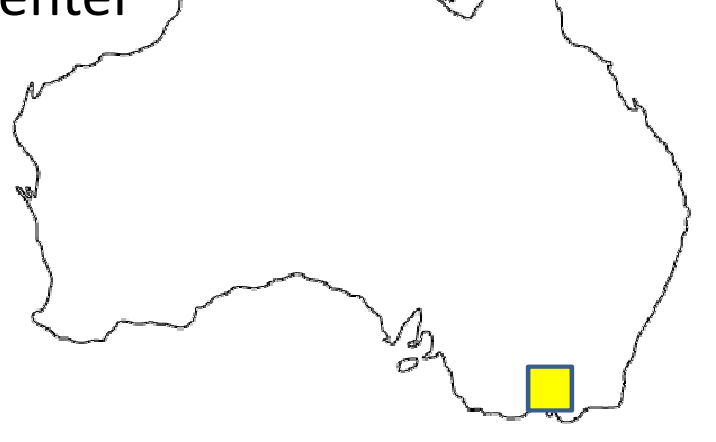




\section{Organovo Has Used The Past 12 Months and Initial Seed Funding to Make Major Strides}

- Moved operations forward - opened site in San Diego, tech transfer from University of Missouri (10 employees)

- Advanced the science - New NIH grant September 1, animal studies by U. Missouri, blood vessel proof of concept trial design w/U.

Wisconsin, primary human cells in use

- Printer development project - first new top of the line printers delivered and ready for wide research use

- Confirmed the market - Quantitative and qualitative market research that gives high confidence in the business plan

- Created new markets - Bioprinter market plans are being executed

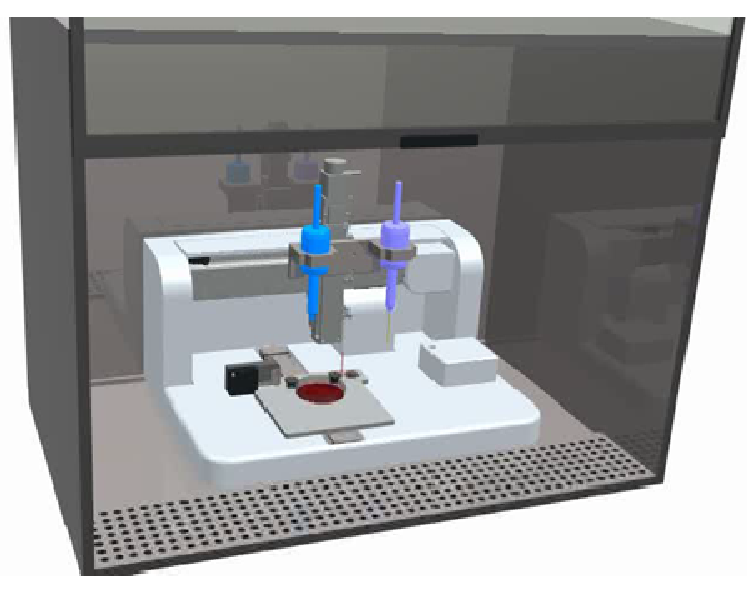




\section{organ vo"}

Investor information:

Keith Murphy, CEO

(310) 729-9053

kmurphy@organovo.com

Website:

http://www.organovo.com 